\title{
Mechanical Jaundice and Bile Duct Stricture Caused by the Migration of Endoclip and Silk Suture Material into the Common Bile Duct
}

\author{
Şükrü Çolak, Hasan Bektaş and Bünyamin Gürbulak \\ Department of General Surgery, Istanbul Training and Research Hospital, Fatih, Istanbul, Turkey
}

\begin{abstract}
It is quite rare the migration of metal clips and silk suture materials into the common bile duct (CBD) that were used for the closure of cystic duct in conventional or laparoscopic cholecystectomy. The most common cause of postoperative jaundice is unrecognised or overlooked stones in the bile ducts during operation. The authors present four patients who developed jaundice and in one case biliary tract stricture, caused by the migration of metal clip and silk suture material into CBD following conventional and laparoscopic cholecystectomy. The migration of endoclip and suture material in to CBD is very rare and it should be kept in mind in post-cholecystectomy jaundice.
\end{abstract}

Key Words: Cholecystectomy, Endoclip migration, Mechanical jaundice, Endoscopic retrograde cholangiopancreatography.

How to cite this article: Çolak Ş, Bektaş H, Gürbulak B. Mechanical Jaundice and Bile Duct Stricture Caused by the Migration of Endoclip and Silk Suture Material into the Common Bile Duct. J Coll Physicians Surg Pak 2020; 30(06):646-649 https://doi.org/10.29271/jcpsp.2020.06.646.

\section{INTRODUCTION}

Cholecystectomy is one of the most common operations performed in general surgery clinics. Due to advances in technology, conventional cholecystectomy has been performed by laparoscopic method, which is a minimally invasive procedure since $1985 .{ }^{1}$ Inaddition to the advantages of laparoscopic cholecystectomy, migration of clip into CBD is a very rare complication; and it was first described in 1992 by Raoul et al. ${ }^{2}$ The mechanism of migration of the clip into the CBD is unknown and occurs days to years after the operation. ${ }^{3}$

The authors presented the cases of jaundice and biliary tract stricture caused by the migration of endoclip and silk suture material in to CBD in post cholecystectomy period.

\section{CASE REPORT}

Case 1: The patient was 45-year old woman who had a history of laparoscopic cholecystectomy 10 years ago, presented with itching, nausea and abdominal pain. Physical examination revealed mild tenderness in the right upper quadrant of the abdomen.

Correspondence to: Bünyamin Gürbulak, Department of General Surgery, Istanbul Training and Research Hospital, Fatih 34098, Istanbul, Turkey

E-mail: bgurbulak@gmail.com

Received: May 09, 2019; Revised: August 20, 2019;

Accepted: September 16, 2019

DOI: https://doi.org/10.29271/jcpsp.2020.06.646
The laboratory values of the patient were as aspartate aminotransferase (AST): $331 \mathrm{u} / \mathrm{L}$, alanine aminotransferase (ALT): $458 \mathrm{u} / \mathrm{L}$, gamma glutamyl transpeptidase (GGT): $752 \mathrm{iu} / \mathrm{L}$, alkaline phosphatase (ALP): $630 \mathrm{mg} / \mathrm{dL}$, total biluribine (T. Bil): 4.3 $\mathrm{mg} / \mathrm{dl}$, direct biluribine (D. Bil): $2.3 \mathrm{mg} / \mathrm{dl}$, and leukocyte count (WBC): 9500 abdominal ultrasonography (US), showed that diameter of the CBD was $11 \mathrm{~mm}$ and intra-hepatic biliary tract was slightly dilated. Upper abdomen magnetic resonans imaging (MRI) and magnetic resonans cholangiography (MRCP) were performed to investigate the CBD pathology. On MRI, clips in the gallbladder bed, enlargement in the CBD up to $9 \mathrm{~mm}$, and heterogeneous signals were observed. In ERCP, the CBD was $12-\mathrm{mm}$ in size and intra-hepatic biliary tract dilatation was detected. Filling defect was present in the distal part of the CBD. After sphincterotomy, CBD exploration was performed with a balloon catheter and the endoclip with plenty of sludge and stone was removed (Figure $1 a$ and $b$ ). The patient was followedup for 5 years and his biochemical values and radiological imaging remained normal.

Case 2: The patient was 46-year woman, who had a history of laparoscopic cholecystectomy 17 years ago; and was referred to the endoscopy unit for ERCP due to the diagnosis of acute cholangitis caused by stone in the CBD. Computerised tomography $(C T)$ scan of patient revealed clips in gallbaldder bed and in CBD. CT showed the diameter of CBD $15 \mathrm{~mm}$ and intrahepatic bile duct dilatation combined with the $13 \times 7 \mathrm{~mm}$ stone formation in distal CBD (Figure 2a and b).

The laboratory values of patient were as AST: $135 \mathrm{u} / \mathrm{L}, \mathrm{ALT}: 77$ u/L, and GGT: $196 \mathrm{iu} / \mathrm{L}, \mathrm{ALP}: 155 \mathrm{mg} / \mathrm{dL}$. In ERCP, stricture of CBD 
was seen at $1 \mathrm{~cm}$ below the hepatic bifurcation and dilatation of intrahepatic biliary tract up to $12 \mathrm{~mm}$. Diameter of distal part below the stricture was $10 \mathrm{~mm}$ in size. A filling defect was also present. After sphincterotomy, sludge and two endoclips were removed from the distal part of $C B D$ with basket catheter. Because of the difficulty in excretion of the contrast material in the proximal part of the CBD stricture, dilatation was performed firstly and then a 8.5 -French $10-\mathrm{cm}$ plastic biliary stent (PBS) was inserted for improving stricture.

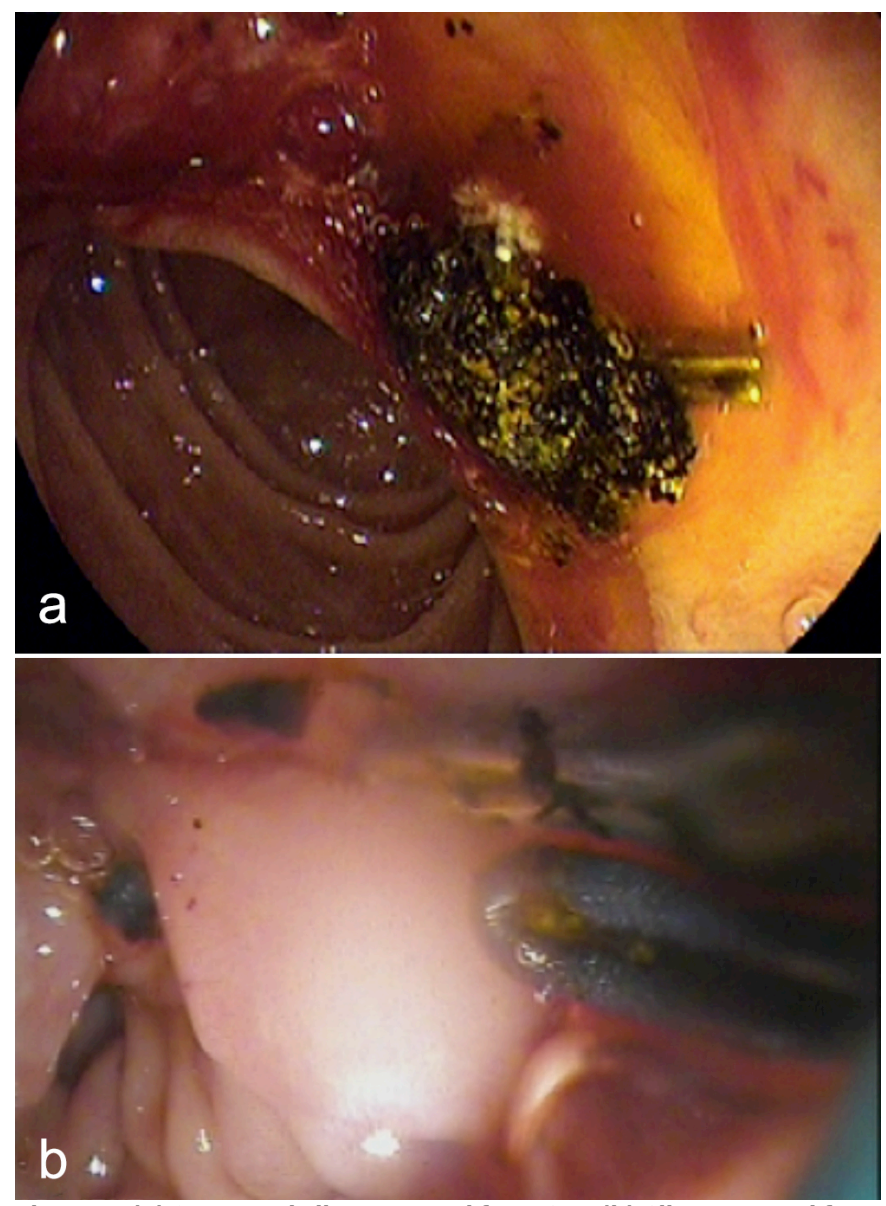

Figure 1: (a) Stone and clips removed from CBD (b) Clips removed from CBD.

ERCP was performed five times consecutively for biliary stricture and five PBS was inserted for improving the stricture. All PBS were removed in the sixth ERCP procedure. Control cholangiography showed that the stricture of CBD had improved. Biochemistry and imaging studies did not show any abnormality during a follow-up period of first year.

Case 3: The patient was 82 years old woman who had a history of conventional cholecystectomy 15 years ago. She was admitted with the complaint of abdominal pain and diagnosis of choledocholithiasis. In MRCP; signal void in CBD is 16-mm in size and intrahepatic biliary tract dilation were detected. The laboratory values of patient as follows: AST: $135 \mathrm{u} / \mathrm{L}, \mathrm{ALT}: 77 \mathrm{u} / \mathrm{L}$, GGT: 196 iu/L, ALP: 155 mg/dL, T.Bil: 1.7 mg/dl, D.Bil: 0.9 mg/dl and WBC:11, 790. In ERCP, silk suture matrix was removed from the distal part of the CBD with basket catheter, and due to the big size of the stones, multiple biliary stents were inserted. In the fifth ERCP procedure all biliary stents were removed and the stones were cleared. Biochemistry and imaging studies were normal during the follow-up period of patient.
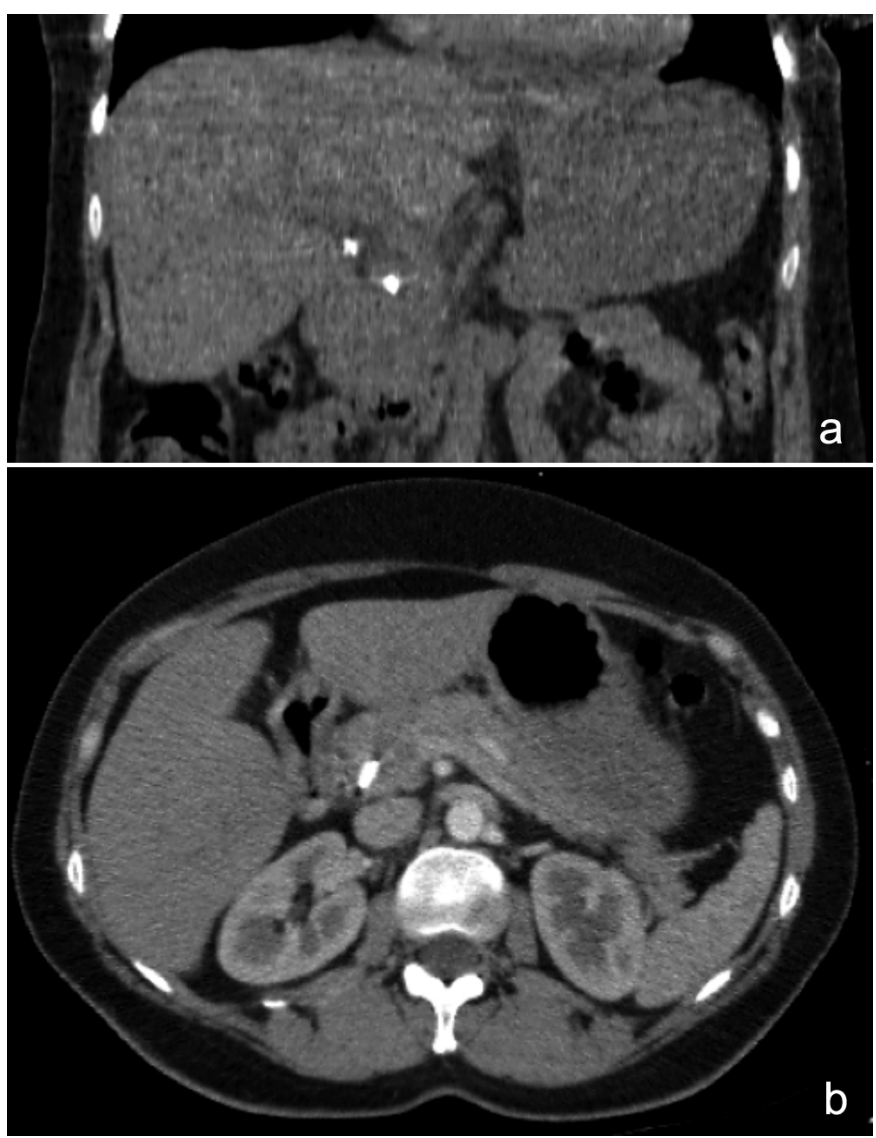

Figure 2: (a) Metallic artifact in gallbladder bed and CBD (b) Metallic artifactin CBD.

Case 4: The patient was 59-year old woman who had a history of conventional cholecystectomy 1.5 years ago and was admitted with the diagnosis of choledocholithiasis and jaundice. In MRCP; signal void in CBD and intrahepatic biliary tract dilation were detected. The laboratory values of patient as follows: AST: $65 \mathrm{u} / \mathrm{L}$, ALT: 102 u/L, GGT: 308 iu/L, ALP: 141 mg/dL, T.Bil: 3.61 mg/dl, D.Bil: $2.39 \mathrm{mg} / \mathrm{dl}$ and WBC: 5990. In ERCP, silk suture material and stone in size of 13-mm were removed from the distal part of CBD with a basket catheter (Figure 3). In control cholangiography, the residual stones were found and then cleared. Biochemistry and imaging studies were normal at followup period of the patient.

\section{DISCUSSION}

There is not reliable data about the long-term behaviour of metal clips and suture materials used for the ligation of the cystic duct and artery in conventional and laparoscopic cholecystectomy performed for gallbladder stone and polyps. In rare cases, migration of these endoclips in CBD is reported to lead to choledocholithiasis, cholangitis, acute pancreatitis, clip embol-ism and duodenal ulcer. ${ }^{4}$ After laparoscopic cholecystectomy, migration of the clip into the CBD was reported by Raoul etal. in $1992{ }^{2}$ 

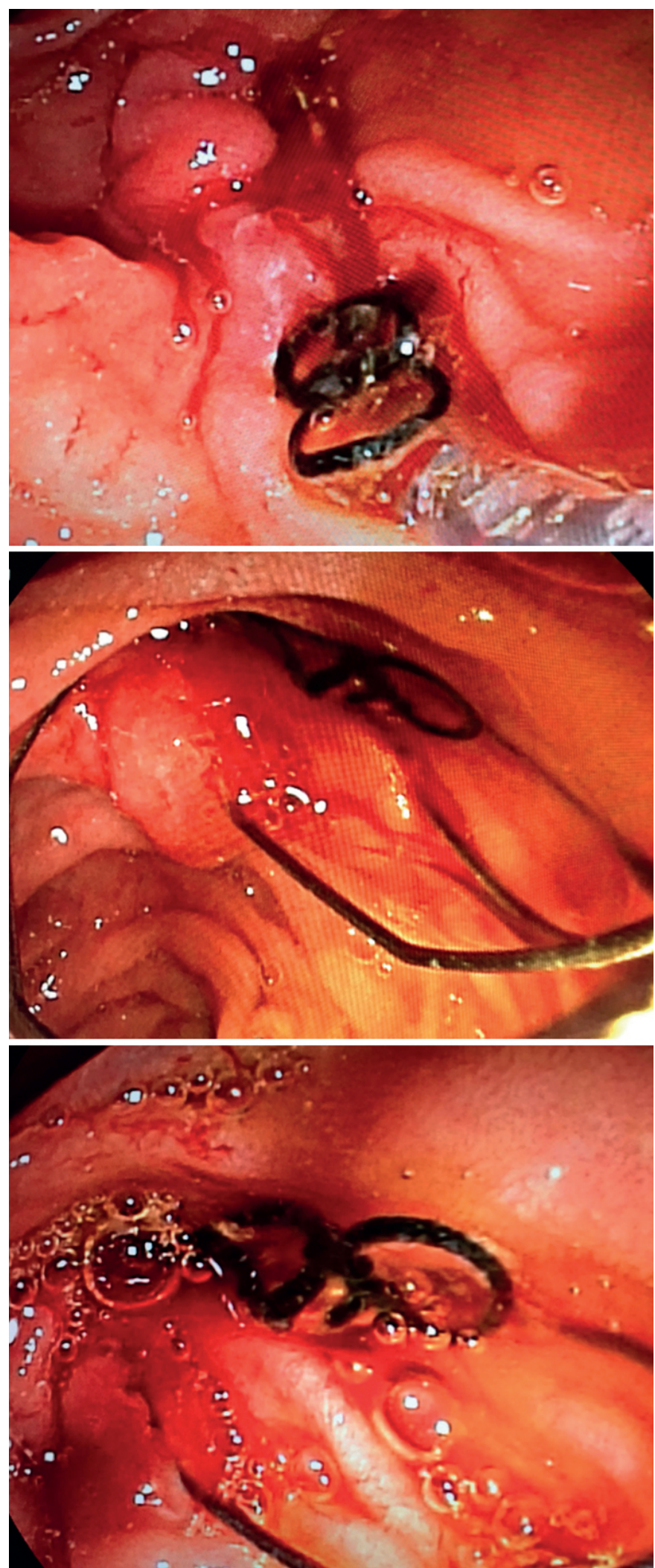

Figure 3: Silksuture matrix removing from ampulla.

The mechanism of migration of clips to the CBD used for ligation of cystic duct has not been fully explained. After laparoscopic cholecystectomy, the migration of the clips in to CBD has been reported in various publications for 11 days to 6 years. ${ }^{5}$
The hypotheses proposed in this regard are similar, but according to the first hypothesis, bilioma is caused by inability to closure of the cystic duct by clip which causes bile leakage. This bilioma causes chronic inflammation and necrosis of the cystic duct stump. The clip, which has been released from the necrotic cystic duct stump, mechanically passes through the bile duct by abrading the wall of the CBD. According to the other hypothesis, the clip gets freed by eroding the bile duct due to local inflammation and migrate in to the CBD.

Short cystic duct or cystic artery, clipping near the CBD, local suppurative complications, and ductal wall ischemia (extreme dissection) are risk factors for clip migration. ${ }^{6}$

The migration of the clips to the bile ducts may cause complications such as pancreatitis, cholangitis, obstruction of the biliary tract and stricture in addition to the formation of nidus for the stones in the CBD. There are very few publications in the literature about the rare complications of the clip except by stone. ${ }^{4,7}$ These patients usually present with any degree of abdominal pain, jaundice or cholangitis. Abdominal US is the first radiological examination. Dilatation of CBD and intrahepatic bile ducts can be detected in USG. Upper abdominal MRI and MRCP are performed for evaluation of the lesion within the CBD. The authors performed USG in both of them and CT scan in one. Both patients were not diagnosed for the migration of the clip into the CBD before ERCP. If a clip has migrated into the CBD and combined with CBD stones are detected, ERCP should be performed to remove clip or stone. ${ }^{2,6}$ However, surgery or percutaneous transhepatic cholangiography can be performed in patients with additional pathology or unsuccesfull ERCP procedure. ${ }^{4,6}$

For the second patient, the migration of the clip into CBD caused formation of stone and biliary stricture. In this patient, it was thought that the cystic duct clip was placed near the main bile duct and a short cystic duct. The management of this patient was quite difficult and prolonged. She was treated by repeated endoscopic dilatation and multiple PBS placements. ${ }^{8}$ Five PBS were inserted in a 2-week interval in to CBD. All stents were removed one month after the last procedure. In order to avoid such complications after laparoscopic- cholecystectomy, care should be taken for clipping, the clips should be at a sufficient distance from the CBD; and unnecessary procedures that forced the security of the clips should be avoided. However, there are publications regarding the use of costly absorbable clips and suture materials to prevent clip migration and the related complications. ${ }^{9}$

As with all foreign bodies left in the abdomen, it should be kept in mind that the clips or suture materials such as silk used for during conventional or laparoscopic cholecystectomy can migrate into the luminal tracts. This is very rare and may cause stricture in the CBD. ERCP plays an important role in treatment. The removal of the stone and other complication management can be performed successfully with ERCP. 


\section{CONFLICT OF INTERESTS:}

The authors declared no conflict of interest.

\section{PATIENTS' CONSENT:}

Written informed consents were obtained from all the patients included in this study.

\section{AUTHORS' CONTRIBUTION:}

ŞÇ: Data collection and writing.

BG: Design and data collection.

HB: Concept and critical review.

\section{REFERENCES}

1. Reynolds W. The first laparoscopic cholecystectomy. JSLS 2001; 5(1):89-94.

2. Raoul JL, Bretagne JF, Siproudhis L, Heresbach D, Campion JP, Gosselin M. Cystic duct clip migration into the common bile duct: A complication of laparoscopic cholecystectomy treated by endoscopic biliary sphincterotomy. Gastrointest Endosc 1992; 38(5):608-11.

3. Onghena T, Vereecken L, Van den Dwey K, Van Loon C. Common bile duct foreign body: An usual case. Surg Laparosc Endosc 1992; 2(1):8-10.

4. Dolay K, Alis H, Soylu A, Altaca G, Aygun E. Migrated endoclip and stone formation after cholecystectomy: A new danger of acute pancreatitis. World J Gastroenterol 2007; 13(47):6446-8.

5. Arnaud JP, Bergamaschi R. Migration and slipping of metal clips after celioscopic cholecystectomy. Surg Laparosc Endosc 1993; 3(6):487-8.

6. Tsumura H, Ichikawa T, Kagawa T, Nishihara M, Yoshikawa K, Yamamoto G. Failure of endoscopic removal of common bile duct stones due to endo-clip migration following laparoscopic cholecystectomy. J Hepatobiliary Pancreat Surg 2002; 9(2):274-7.

7. Benatta MA, Barthet M, Desjeux A, Grimaud JC. Endoscopic extraction of biliary stones and a migrated endoclip for acute pancreatitis. Hepatobiliary Surg Nutr 2015; 4(3): 216-7.

8. Bektaş H, Gürbulak B, Şahin ZD, Düzköylü Y, Çolak Ş, Gürbulak EK, et al. Multiple plastic biliary stent placement in the management of large and multiple choledochal stones: Single center experience and review of the literature. Wideochir Inne Tech Maloinwazyjne 2017; 12(3):231-7.

9. Allan A, Cooper MJ, Leaper DJ. A new absorbable ligating clip for use in cholecystectomy. J R Coll Surg Edinb 1984; 29(1):53-4. 